\title{
Raças de Heterodera glycines na região Nordeste de Mato Grosso do Sul
}

\author{
Guilherme L. Asmus ${ }^{1}$, Thiago S. Teles ${ }^{2}$, Jefferson Anselmo ${ }^{3} \&$ Giovana T. Rosso $^{4}$ \\ ${ }^{1}$ Embrapa Agropecuária Oeste, Cx. Postal 661, 79804-970, Dourados, MS, Brasil; ${ }^{2}$ Centro Universitário da Grande Dourados, \\ 79824-900, Dourados, MS, Brasil; ${ }^{3}$ Fundação Chapadão, Cx. Postal 39, Chapadão do Sul, MS, Brasil; ${ }^{4}$ Universidade Estadual \\ de Mato Grosso do Sul, Cx. Postal 351, 79804-970, Dourados, MS, Brasil
}

Autor para correspondência: Guilherme L.Asmus, e-mail: asmus@cpao.embrapa.br

\section{RESUMO}

O nematoide de cisto da soja, Heterodera glycines, constitui-se em um dos principais entraves à produção de soja na região Nordeste de Mato Grosso do Sul. Após um período de uso do manejo recomendado para as áreas infestadas, observou-se a ressurgência de altas densidades populacionais associada a severos danos à cultura, mesmo com a utilização de cultivares resistentes, fato que conduziu à hipótese da ocorrência de mudança nas raças do nematoide. Assim, nas safras de 2006/2007 e 2007/2008, foram amostradas lavouras de 22 propriedades nos municípios de Água Clara, Chapadão do Sul e Costa Rica, com presença confirmada de altas populações de $H$. glycines. Após serem multiplicadas em soja cv. BRS 133 por até três gerações, as populações oriundas de cada amostra foram submetidas ao teste padrão para a determinação de raças, com a inclusão da variedade diferenciadora Hartwig, visando detectar eventual presença das raças $4^{+}$ ou $14^{+}$. Detectou-se a presença de quatro raças, com predominância da raça 4 (72,73\% das amostras), seguida das raças 14,5 e 6 (18,19\%, $4,54 \%$ e $4,54 \%$ das amostras, respectivamente). Conclui-se que não houve significativa alteração nas raças de $H$. glycines que ocorrem na região Nordeste de Mato Grosso do Sul.

Palavras-chave: Glycine max, distribuição, manejo, nematoide de cisto da soja, variabilidade.

\begin{abstract}
Races of Heterodera glycines in the Northeast of Mato Grosso do Sul, Brazil

The soybean cyst nematode (SCN), Heterodera glycines, is one of the major constraint to soybean production in the Northeast of the Mato Grosso do Sul State, Brazil. After a period of recommended management of infested areas, the recent resurgence of high population densities and severe damage to soybeans, regardless of the use of resistant cultivars, has led to the hypothesis that nematode races could be changing. Thus, in 2006/2007 and 2007/2008 growing seasons, highly infested soil from 22 farms in the municipalities of Água Clara, Chapadão do Sul and Costa Rica were sampled. After being multiplied in soybean cv. BRS 133 for up to three generations, the SCN populations from each soil sample were submitted to standard test for the determination of races, adding the cultivar Hartwig as one of the differential hosts to eventually detect the possible presence of races $4^{+}$or $14^{+}$. Among the four races detected, the race 4 was predominant $(72.73 \%$ of samples), followed by races 14,5 and $6(18.19 \%, 4.54 \%$ and $4.54 \%$ of the samples, respectively). There was no significant change in the races of $H$. glycines in the Northeast of the Mato Grosso do Sul State, Brazil.
\end{abstract}

Key words: Glycine max, distribution, management, soybean cyst nematode, variability.

A ocorrência do nematoide de cisto da soja (NCS), Heterodera glycines Ichinohe 1952, no Estado de Mato Grosso do Sul data de 1992 (Monteiro \& Morais, 1992). Desde então, as regiões Norte e Nordeste do Estado convivem com o nematoide que se constitui em um dos principais entraves à produção de soja (Tecnologias..., 2008). Especificamente nos municípios de Água Clara, Chapadão do Sul e Costa Rica, na região Nordeste, onde são cultivados cerca de 170 mil hectares de soja, os danos causados pelo NCS têm sido elevados.

A variabilidade genética de $H$. glycines no Brasil temse mostrado maior que a observada em outros países. Até o momento, com base na metodologia usual para definição de raças (Riggs \& Schmitt, 1988), foram encontradas as raças $1,2,3,4,5,6,9,10$ e 14 , além de $4^{+}$e $14^{+}$. As duas últimas se referem a raças que diferem das raças 4 e 14 clássicas, por apresentarem habilidade de parasitar a cultivar norteamericana Hartwig, até então considerada resistente a todas as raças (Dias et al., 2006). Nos estados de Goiás, Mato Grosso e Mato Grosso do Sul, a evolução de raças com genes adicionais de parasitismo tem acontecido de forma muito rápida (Dias et al., 2010).

Embora baseado em reduzido número de amostras, um levantamento de raças do NCS nos municípios de Chapadão do Sul (MS) e Chapadão do Céu (GO) revelou a prevalência das raças 4 e 6 em Mato Grosso do Sul e da raça 10 em Goiás (Asmus, 2002). Além dessas, já foram detectadas as raças 3, 5, 9 e 14 na região, porém em proporções não definidas (Tecnologias..., 2008).

Após a detecção na região em 1992, o NCS tem sido manejado por meio de rotação de culturas com espécies não hospedeiras, principalmente milho e algodoeiro, 
e utilização de cultivares de soja resistentes, embora poucas destas apresentem resistência a todas as raças que ocorrem na região. O ressurgimento de áreas com altas densidades populacionais do nematoide e severos danos à soja, independente da utilização de cultivares resistentes, conduziram à hipótese de que esteja ocorrendo mudança nas raças do nematoide na região. Assim, realizou-se um levantamento com o objetivo de atualizar o conhecimento a respeito das raças do NCS que ocorrem no Nordeste de Mato Grosso do Sul.

Durante os anos agrícolas de 2006/2007 e 2007/2008 realizou-se um levantamento das raças do NCS que ocorreram nos municípios de Água Clara, Chapadão do Sul e Costa Rica. Em cada uma das safras agrícolas mencionadas, durante os meses de fevereiro e março, foram visitadas lavouras com presença do NCS e coletadas amostras compostas de solo, totalizando 22 áreas amostradas. Cada amostra, com aproximadamente $500 \mathrm{~g}$ de solo, composta de 10 a 15 subamostras, foi obtida com trado manual, na profundidade de 0 a 20 $\mathrm{cm}$, homogeneizada, colocada em saco plástico, etiquetada e acondicionada em caixa térmica para ser transportada até o Laboratório de Nematologia da Embrapa Agropecuária Oeste (Dourados, MS). O local de cada amostragem foi georeferenciado com GPS de navegação.

No laboratório, as amostras foram misturadas com areia fina (1:1, v:v) e colocadas em vasos de argila com capacidade para $500 \mathrm{~mL}$, onde foram semeadas sementes de soja da cultivar BRS 133, para multiplicação do nematoide em casa de vegetação. Após 90 dias, cistos e fêmeas foram separados das raízes com jatos de água, sobre peneiras de malha de $850 \mu \mathrm{m}$ e $180 \mu \mathrm{m}$, e esmagados sobre peneira de $150 \mu \mathrm{m}$ com o fundo de um Becker de vidro de $100 \mathrm{~mL}$ para liberação dos ovos, que foram recolhidos em peneira de 25 $\mu \mathrm{m}$. Os ovos retidos na peneira de $25 \mu \mathrm{m}$ foram purificados por centrifugação e quantificados em câmara de Peters para serem utilizados como inóculo.

Para a determinação das raças, utilizou-se a série de cultivares diferenciadoras, de acordo com metodologia descrita por Riggs \& Schmitt (1988), acrescida da cultivar Hartwig, de maneira a permitir a detecção das raças $4^{+}$e $14^{+}$. A cultivar Lee 74 foi utilizada como padrão de suscetibilidade. Os testes para a determinação das raças foram conduzidos em casa de vegetação, em delineamento inteiramente casualizado, com sete repetições. Cada repetição foi constituída de uma planta de soja cultivada em copo de isopor, contendo $300 \mathrm{~mL}$ de uma mistura de solo+areia $(1: 1)$ desinfestada por solarização, inoculada no estádio fenológico V1 com 4000 ovos do nematoide contidos em $5 \mathrm{~mL}$ de suspensão aquosa.

Entre 32 e 35 dias após a inoculação, as fêmeas de $H$. glycines foram separadas das raízes utilizando-se a mesma metodologia citada anteriormente e quantificadas em placas plásticas quadriculadas em microscópio estereoscópico binocular (40x). Os testes foram conduzidos durante os anos de 2009 e 2010 , evitando-se os meses de temperaturas extremas (quente ou frio) do ano, quando o desenvolvimento do nematoide e a taxa de reprodução são reduzidos.

A partir do número de fêmeas obtidas nas contagens, determinou-se a raça de cada população por meio do cálculo do índice de fêmeas (percentagem de fêmeas na raiz da variedade diferenciadora em relação ao número de fêmeas na variedade Lee 74), conforme Riggs \& Schmitt (1988).

Observou-se considerável variabilidade do NCS na região de produção de soja da região Nordeste de Mato Grosso do Sul, com a presença das raças 4, 5, 6 e 14, e clara prevalência da raça 4 (Tabela 1 e Figura 1). Estes resultados confirmam as informações de trabalhos anteriores (Asmus, 2002; Dias et al., 2006), que apontaram a ocorrência das mesmas raças, além das raças 9 e 10.

O manejo do NCS no Brasil é realizado principalmente pela rotação de culturas com espécies não hospedeiras e pelo uso de cultivares resistentes de soja (Tecnologias..., 2008). No entanto, são raras as cultivares com resistência a outras raças que não as raças 3 e 1 , as mais frequentes nas diversas regiões produtoras de soja do Brasil e do mundo (Niblack, 2002; Dias et al., 2006). Considerando-se que as raças 4 e 14 estão presentes em mais de $90 \%$ das áreas infestadas amostradas

TABELA 1 - Municípios e coordenadas geográficas dos locais de coleta de solo de lavouras de soja infestadas por Heterodera glycines, na região Nordeste de Mato Grosso do Sul, e respectivos resultados dos testes de identificação de raça

\begin{tabular}{|c|c|c|}
\hline Município & Coordenadas & Raça \\
\hline Água Clara & $19^{\circ} 18^{\prime} 5297^{\prime \prime} \mathrm{S} / 53^{\circ} 09^{\prime} 0899^{\prime \prime} \mathrm{W}$ & 14 \\
\hline Água Clara & $19^{\circ} 18^{\prime} 5297^{\prime \prime S} / 53^{\circ} 09^{\prime} 3294^{\prime \prime W}$ & 4 \\
\hline Água Clara & $19^{\circ} 10^{\prime} 3633^{\prime \prime} \mathrm{S} / 53^{\circ} 09^{\prime} 5241^{\prime \prime W}$ & 4 \\
\hline Água Clara & $19^{\circ} 19^{\prime} 4941^{\prime \prime S} / 53^{\circ} 11^{\prime} 4538^{\prime \prime W}$ & 4 \\
\hline Água Clara & $19^{\circ} 18^{\prime} 2156^{\prime \prime} \mathrm{S} / 53^{\circ} 09^{\prime} 2467^{\prime \prime W}$ & 4 \\
\hline Água Clara & $19^{\circ} 14^{\prime} 4419^{\prime \prime} \mathrm{S} / 53^{\circ} 07^{\prime} 5763^{\prime \prime W}$ & 4 \\
\hline Chapadão do Sul & $18^{\circ} 45^{\prime} 1697^{\prime \prime} \mathrm{S} / 52^{\circ} 36^{\prime} 1542^{\prime \prime} \mathrm{W}$ & 4 \\
\hline Chapadão do Sul & $18^{\circ} 46^{\prime} 5764^{\prime \prime} \mathrm{S} / 52^{\circ} 37^{\prime} 4056^{\prime \prime W}$ & 4 \\
\hline Chapadão do Sul & $18^{\circ} 51^{\prime} 1949^{\prime \prime} \mathrm{S} / 52^{\circ} 31^{\prime} 3429^{\prime \prime} \mathrm{W}$ & 4 \\
\hline Chapadão do Sul & $18^{\circ} 52^{\prime} 0308^{\prime \prime} \mathrm{S} / 52^{\circ} 28^{\prime} 4237^{\prime \prime} \mathrm{W}$ & 4 \\
\hline Chapadão do Sul & $18^{\circ} 51^{\prime} 1458^{\prime \prime} \mathrm{S} / 52^{\circ} 33^{\prime} 1651^{\prime \prime W}$ & 14 \\
\hline Chapadão do Sul & $18^{\circ} 44^{\prime} 8321^{\prime \prime S} / 52^{\circ} 40^{\prime} 7219^{\prime \prime} \mathrm{W}$ & 4 \\
\hline Chapadão do Sul & $18^{\circ} 44^{\prime} 0506^{\prime \prime} \mathrm{S} / 52^{\circ} 44^{\prime} 6878^{\prime \prime} \mathrm{W}$ & 4 \\
\hline Chapadão do Sul & $18^{\circ} 49^{\prime} 1632^{\prime \prime} \mathrm{S} / 52^{\circ} 39^{\prime} 1632^{\prime \prime} \mathrm{W}$ & 4 \\
\hline Costa Rica & $18^{\circ} 08^{\prime} 5674^{\prime \prime} \mathrm{S} / 53^{\circ} 08^{\prime} 0371^{\prime \prime W}$ & 14 \\
\hline Costa Rica & $18^{\circ} 08^{\prime} 5609^{\prime \prime} \mathrm{S} / 53^{\circ} 08^{\prime} 0508^{\prime \prime} \mathrm{W}$ & 14 \\
\hline Costa Rica & $18^{\circ} 18^{\prime} 6850^{\prime \prime} \mathrm{S} / 53^{\circ} 06^{\prime} 8805^{\prime \prime} \mathrm{W}$ & 4 \\
\hline Costa Rica & $18^{\circ} 18^{\prime} 4197^{\prime \prime} \mathrm{S} / 53^{\circ} 06^{\prime} 9604^{\prime \prime W}$ & 4 \\
\hline Costa Rica & $18^{\circ} 19^{\prime} 2889^{\prime \prime} \mathrm{S} / 53^{\circ} 06^{\prime} 6363^{\prime \prime W}$ & 5 \\
\hline Costa Rica & $18^{\circ} 27^{\prime} 5472^{\prime \prime} \mathrm{S} / 53^{\circ} 14^{\prime} 2616^{\prime \prime W}$ & 4 \\
\hline Costa Rica & $18^{\circ} 17^{\prime} 9650^{\prime \prime} \mathrm{S} / 53^{\circ} 06^{\prime} 8945^{\prime \prime W}$ & 6 \\
\hline Costa Rica & Faz. Cascata* & 4 \\
\hline
\end{tabular}

*não foi possível obter a posição geográfica 


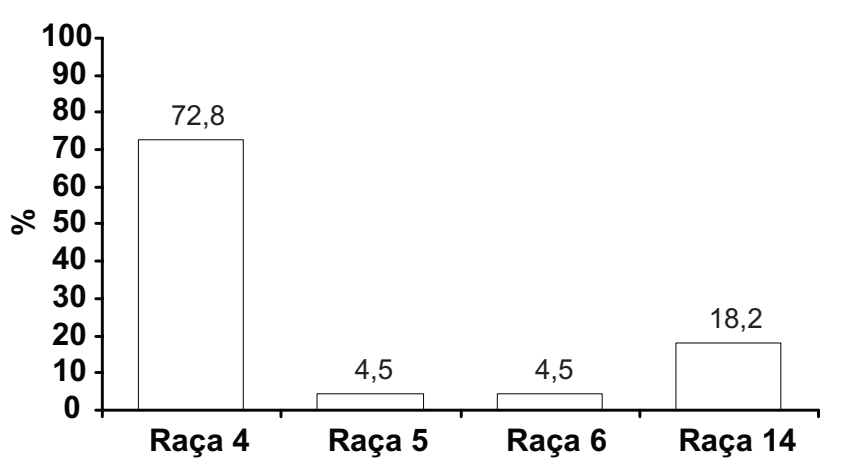

FIGURA 1 - Percentagem de ocorrência das raças de Heterodera glycines em amostras de solo de lavouras infestadas na região Nordeste de Mato Grosso do Sul.

no Nordeste de MS, o manejo do NCS nessa região deve ser, prioritariamente, realizado com a rotação de culturas. Esforços devem ser dedicados ao desenvolvimento de cultivares resistentes a essas raças.

\section{AGRADECIMENTOS}

Os autores agradecem ao Técnico de Laboratório Alex Sandro Vicentin Lima, da Embrapa Agropecuária Oeste, pelo apoio na condução do trabalho.

\section{REFERÊNCIAS BIBLIOGRÁFICAS}

Asmus GL (2002) Monitoramento de raças do nematoide de cisto da soja em áreas infestadas de Mato Grosso do Sul e Goiás. Resumos. Reunião de Pesquisa de Soja da Região Central do Brasil, 24. Londrina PR. Embrapa Soja.

Dias WP, Silva JFV, Garcia A (2006) Nematoides de importância para a soja no Brasil. In: Suzuki S, Yuyama MM, Camacho AS (Eds.) Boletim de pesquisa de soja 2006. Rondonópolis MT. Fundação MT. pp. 139-151.

Dias WP, Asmus GL, Silva JFV, Garcia A, Carneiro GES (2010) Nematoides. In: Almeida AMR, Seixas CDS (Eds.) Soja: doenças radiculares e de hastes e inter-reações com o manejo do solo e da cultura. Londrina PR. Embrapa Soja. pp. 173-206.

Monteiro AR, Morais SRAC (1992) Ocorrência do nematoide de cistos da soja, Heterodera glycines Ichinohe, 1952, prejudicando a cultura no Mato Grosso do Sul. Nematologia Brasileira 16:101-102.

Niblack TL (2002) The race concept. In: Riggs RD, Wrather JA (Eds.) Biology and management of the soybean cyst nematode. St. Paul MN. APS Press. pp. 73-86.

Riggs RD, Schmitt DP (1988) Complete characterization of the race scheme for Heterodera glycines. Journal of Nematology 20:392-395.

Tecnologias de produção de soja - Região Central do Brasil 2009 e 2010. 2008. Londrina PR. Embrapa Soja. (Sistemas de Produção, 13).

TPP 429 - Recebido 14 Outubro 2011 - Aceito 15 Março 2012 Editor de Seção: Rosângela D'Arc L. Oliveira 